\title{
Countermeasures and Some Prominent Problems Affecting the Employment of College Students
}

\author{
Hongying $\operatorname{Sun}^{1}$ Yong Wei, Guimei Dong, Renjie Yang, \\ Tianjin Agricultural University \\ College of Engineering and Technology \\ Tianjin, 300384, China
}

\begin{abstract}
With the expansion of college enrollment, the growth rate of graduates is greater than that of demand, and more and more college students move to the job market. There are some problems, such as uneven development of various schools, imbalanced direction of graduates, increasingly prominent contradiction between professional establishment of colleges and market, inaccurate employment choices of college students, and high consumption of talents in employing departments, so the overall employment situation of college graduates tends to be tense. This paper analyzes the problems existing in the employment process of college students and puts forward the corresponding solutions, so as to effectively resolve the contradiction between supply and demand.
\end{abstract}

\section{Keywords-Employment; Graduate; Development}

\section{SOME PROMINENT PROBLEMS AFFECTING THE EMPLOYMENT OF COLLEGE STUDENTS}

To promote the full employment of college students is both a national policy and people's livelihood. The employment of college students is not only related to whether individual investment in higher education can obtain the expected income, but also to the behavior of people investing in higher education, but also to the effective allocation of human resources and the sustainable development of economy and society. In recent years, many scholars have tried to prove that the contradiction between the increasing number of college students' employment caused by the expansion of higher education in our country and the relative reduction of social employment posts is the root of the problem of college students' employment difficulties. In fact, the difficulty of obtaining employment for college students can be attributed not only to the problems of higher education itself, but also to the development of the lab our market. The degree and operation mechanism are closely related. At present, the change of employment environment and the development of labor market for college students in our country have provided an opportunity to enhance the adaptability of talent training mode of higher education to the demand of talents in the labor market and to promote the employment of college students.

\section{A. College students' unhealthy psychology of choosing a job}

The mentality of college graduates has always been an important variable which leads to difficulties in employment, which mainly shows that their own orientation is inconsistent with social evaluation, high and low, and it is impractical to choose a job. Contemporary college graduates have different psychological phenomena in different stages of employment.
The common unhealthy psychological phenomena in the stage of preparation for employment are dependence, wait and see, inferiority complex, slackness. In the process of choosing a job, the bad psychological phenomena are money worship, pursuit of stability, conceit, jealousy and comparison. "Jobhopping", "muddling along", etc.

The psychological problems and other external factors of college students' career choice mainly include: first, the students' own factors, such as the strong sense of anxiety, the contradiction between ideal and reality, the contradiction between major and love, and the contradiction between major and region. The contradiction between material benefits and spiritual needs is quite prominent; second, social environmental factors are: increasingly serious employment situation, complex social interpersonal relations, high consumption of talents, etc.; third, school education factors: school employment education and guidance are not in place. Not deep, not thorough, it is easy to make students psychological problems.

\section{B. Lack of honesty and credit in college students' employment}

The importance of honesty and credit behavior in market economy society is getting more and more attention. The current lack of integrity in college graduates' employment includes resume "water injection", repeated signing, malicious breach of contract and frequent job hopping. From the student's point of view, the students lack understanding of the procedure and policy of employment when they are employed for the first time; the attitude of employment is not correct and the expectation is on the high side; the legal consciousness of responsibility is weak, and they lack the ability of reflection, etc. From the view of objective environment, the utilitarian pursuit of employment rate in colleges and universities is compared with each other, and the phenomenon of "credit crisis" in social environment directly induces and influences the ideological consciousness and behavior of college students, and induces their psychology of seeking profits. In addition, School and family integrity education is weak, integrity evaluation system is not perfect, and the supervision and restriction mechanism of credit imbalance behavior is not perfect. 


\section{Reforming the training Mode of Colleges and Universities}

Carry out innovative training mode, comprehensively improve college students' creative consciousness, professional foundation, practical skills, interpersonal relationship and other comprehensive qualities, bring up compound talents, carry out the training mode adapted to the market, carry out the training mode of adapting to the market, To set up the guiding ideology of "employment-oriented", to re-examine and adjust the structure of discipline and specialty according to the changes of social demand, to reform the teaching contents and methods, and to establish a talent training model adapted to the market economy; In combination with the diversified requirements of the society for various talent specifications, the foster mode should vigorously develop the advantages of specialty, highlight personality, output characteristics and enhance the irreplaceable quality of graduates.At the same time, strengthen the link of practice teaching, develop comprehensive and practical courses, improve students' comprehensive quality.

\section{Employment guidance in Colleges and universities is not in place}

In recent years, college employment guidance work has been paid more attention to, but college students' employment motivation and expectation show diversity and complexity, but the role of employment guidance is very limited in depth and breadth: first, the college employment guidance funds are insufficient. The institutions are incomplete and facilities are not perfect; second, the strength of teachers is weak. Some colleges and universities have only put up a sign in their students' offices and have no full-time staff at all. They are short of staff and lack quality in the in-depth study of employment guidance work. Third, the contents of the guidance are not comprehensive. At present, most of the employment guidance work in colleges and universities is limited to information release, policy guidance, graduate statistics, file distribution, and psychological adjustment of employment. In the aspects of job interview skills, it neglects to shape students' personality and develop their potential, and lacks the cultivation of college students' innovative ability, vocational development education and employment safety education. The employment situation report and lecture are the main ones. The effect of this kind of one-way teaching is not good, and the help to students' employment is not obvious.

\section{E The employing system of the employing unit is} unreasonable

With a surge in the number of college graduates, demand and supply in the job market have changed, and employers have raised recruitment standards. The raising of the threshold for entry by employers has resulted in the graduates being overqualified and their professional skills not being fully developed in their posts. This has formed a huge gap with the mentality of new graduates who want to achieve a career in society. Under such circumstances, college students would rather lose their jobs than take up these jobs. In addition, some employers, in order to save costs or from a practical point of view, constantly recruit college students to their units for internships. At the end of the period, they do not have solid professional knowledge and skills, lack of working experience and communication skills, and lack the ability to communicate. This kind of fraud also affects the employment of college students [1].

\section{COUNTERMEASURES TO THE PROMINENT PROBLEMS OF COLLEGE STUDENTS' EMPLOYMENT}

\section{A. Correction of College students' Employment Psychology}

In view of the current psychological problems of college students' employment, we should carry out ideological and political education from the angle of "rational economic man", pay attention to the economic needs of graduates, promote the life value of graduates to realize their needs, and establish the sense of employment mission of graduates. In order to achieve good results. Therefore, the employment education for college students should be carried out by means of more guidance and education, adhere to the working principle of "differentiated treatment, classified guidance, and step by step", strengthen the education of students' professional ideology and professional ethics, and actively carry out comprehensive work. The development of self-cognition education and psychological orientation education to help students understand themselves correctly; strengthen college students' outlook on life, values education, mental health education Strengthen college students' credit education and establish credit evaluation and supervision mechanism in order to prepare for employment.

\section{B. Perfecting the Credit Management and Supervision Mechanism of College students}

Establish and improve employment laws and regulations to regulate the employment market and the rights, responsibilities and behaviors of all parties. Strengthening the credit construction and management, establishing and perfecting the credit management system and the credit supervision mechanism, such as establishing the internal credit supervision mechanism, the credit supervision mechanism and the credit evaluation mechanism between the school and the employing unit, etc. Strengthen the honesty education of college students, improve the moral accomplishment of graduates, bring the professional ethics education into the employment guidance and career design education, and run through the students' whole college learning career, establish the personal credit record files of college students, Open the Employment Information and Credit Archives of College students and establish strict Employment Materials. The system of examination and contract, the system of breach of contract, the integrity of college students, and the integrity awareness of college students are strengthened, so that the integrity education of college students is really put into practice.

\section{Reforming the training Mode of Colleges and Universities}

The implementation of the training mode of innovation, improve the students innovative consciousness, professional knowledge, practical skills, interpersonal relationship and comprehensive quality, train talents; training mode to market, establish the guiding ideology of the employment oriented, according to the needs of society change, re-examine and adjust the structure of discipline, teaching reform the contents and methods, establish the training mode to adapt to market 
economy talents; training mode to implement interaction, promote the credit system, allowing students to cross system, cross learning, make full use of modern teaching means, strengthening classroom interaction, mobilize the initiative of students, learning the distinctive culture; In combination with the diversified requirements of the society for various talent specifications, the foster mode should vigorously develop the advantages of specialty, highlight personality, output characteristics and enhance the irreplaceable quality of graduates. At the same time, strengthen the link of practice teaching, develop comprehensive and practical courses, improve students' comprehensive quality.

\section{Strengthening College students' Employment guidance and} career Design guidance

According to the employment situation and the situation of educational development, the school should set up a special work force to strengthen the construction of the specialty and discipline of employment guidance from the aspects of institution setting, teaching staff, actual effect of work, employment market, social demand structure, etc.Enrich the theory and method of employment guidance, adjust and perfect the employment guidance mode and scheme in time, such as all-staff type, whole process type, development type of employment guidance.

In order to improve the contents of employment guidance, in addition to the existing education of employment concept, psychological testing and debugging, and job search skills training, we should also provide the opportunity of vocational simulation practice, strengthen the development of students' personality and potential, and cultivate the innovative ability of college students.To strengthen vocational development education and employment safety education, combine the career design guidance of college students with employment guidance, and run through the whole process of study and life, and gradually develop to the goal of systematization, scientization and standardization.

\section{ATTACH IMPORTANCE TO STUDENT PRACTICE AND ESTABLISH LONG-TERM SUPPLY AND DEMAND PARTNERSHIP WITH EMPLOYERS}

Colleges and universities should attach importance to the practice system, and college students' internships can promote graduates to better understand the needs of employers, especially for the professional knowledge and skills that the employers are most concerned about, the ability to solve problems, the ability to communicate and coordinate, and the ability to cooperate. Learning will, dedication and integration with the unit to improve themselves, apply the book knowledge in practice, improve the competitiveness of employment. Colleges and universities should also establish a long-term supply and demand partnership with employers and set up enrollment majors and numbers according to the needs of employers in order to form a stable employment base [2]
IV. THE UNIT OF CHOOSE AND EMPLOY PERSONS SHOULD PAY ATTENTION TO THE TRAINING LINK BEFORE THE POST, CARRY ON THE RATIONAL CONSUMPTION TO THE TALENTED PERSON

Enterprises or employing units hope that college graduates can immediately put into work and create profits for enterprises as soon as they enter the unit. However, because college students are not closely connected with their professional knowledge and skills and practice, they do not understand the enterprises. So that many college students master the knowledge and skills with the requirements of employers have a gap. Therefore, employers should strengthen pre-job training, including pre-job norms, job tasks, corporate culture and career management planning of new employees, so that graduates can have a clear understanding of the future job, so as to adapt to the new job quickly. In addition, employers should recruit according to the demand for jobs, and should not one-sided pursue the high consumption of talents. Now the job market has been "zero-wage employment" phenomenon, but the employment rate is still falling. Because the same jobs are now held by graduates with higher or higher levels of education, but the pay has not improved, some college students wait and see and choose not to work or pursue a higher degree.

\section{PROMOTE THE REFORM OF THE LABOR MARKET AND ACCELERATE THE SMOOTH EMPLOYMENT OF COLLEGE STUDENTS}

At present, on the one hand, the operation of China's labor market is still restricted by the inertia of the planning system, on the other hand, the labor market operating mechanism adapted to the market economy is still in the process of forming. The interweaving of these two forces makes the employment of college students and the cultivation of talents in higher education face more complicated environment and restrictive factors. Therefore, it is imperative to deepen the labor market reform aiming at full employment of college students. First, accelerate the construction of unified labor market, overall planning urban and rural areas, regional employment of college students; standardize income distribution, gradually reduce the income gap between industries and regions; increase employment in the central and western regions. The policy support of college students can alleviate the imbalance of the regional structure of college students' employment. Second, accelerate the information construction of labor market. Adequate labor market information is not only conducive to the timely employment of college students, but also conducive to guide higher education to reform the mode of talent training, and enhance its adaptability to the talent market. The government and employment agencies should speed up the construction of information infrastructure in the labor market, improve the database system of employment information for college students, enterprises and labor market and its publishing mechanism. Accurate transmission of talent demand information to colleges and university students to reduce the cost of information search and information error; The dialogue and communication mechanism between government, 
university and labor market, the timely exchange of problems in the use and cultivation of talents, and the establishment of institutional mechanism for the joint participation of stakeholders in the training of talents in higher education. Third, strengthen the standardized construction of labor market operation. Compared with employers, current university graduates are the weak side of the labor market [3].

\section{CONCLUSION}

Therefore, how to regulate the behavior of employers in the labor market and safeguard the rights and interests of college students is the key to maintain the health of higher education and the fairness of employment. The urgent task is to introduce laws and regulations related to college students' employment, including internships and employment, wage treatment, social security and gender equality, so as to create a good market environment for the fair and just employment of college students [4].

\section{REFERENCES}

[1] Ma Yongxia, Liang Jinhui, A study on the Evaluation of the Employment ability of Science and Engineering College students [M].Educational research, 2016(9):40-49.

[2] Likert, R. A technique for the measurement of attitudes [M]. Archives of Psychology, 1932, 55.

[3] Ma Tingqi, Talent training Mode, Labor Market and College students' Employment [J]. Higher education research, 2013, (3): 34-39.

[4] Hu, L. \& Bentler, P. M. Cut off criteria for fit indexes in covariance structure analysis: Conventional criteria versus new alternations [J]. Structural Equation Modeling, 1999, (6). 